\title{
Genetic analysis in a female manifesting haemophilia B
}

\author{
S. Palmer, G.R. Standen, P. Yates and A. Oakhill ${ }^{1}$
}

Department of Haematology, Bristol Royal Infirmary, Bristol BS2 $8 \mathrm{HW}$ and ${ }^{1}$ Bristol Royal Hospital for Sick Children, St Michael's Hill, Bristol BS2 8BJ, UK

Summary: A 5 year old female child presented with a psoas haematoma as the first manifestation of haemophilia B. Molecular genetic studies were performed to investigate the inheritance of the disorder and the mechanisms by which females may express the haemophilia B phenotype are discussed.

\section{Introduction}

Haemophilia B is an X-linked inherited bleeding disorder, which is due to a deficiency or functional defect of coagulation factor IX circulating in plasma. In rare instances, females may be affected and have factor IX clotting activity sufficiently low to result in haemorrhage. ${ }^{1}$ Such patients are generally carriers with extreme lyonization or, less commonly, females with Turner's syndrome or mosaicism. We describe a young girl with haemophilia B who initialy presented with a psoas haematoma. Family studies were performed to clarify the inheritance of the disorder.

\section{Case history}

A 5 year old female was admitted with a one week history of right leg pain radiating to the knee. The pain developed after a walk and had increased in severity during the 24 hours prior to admission. There was no history of abnormal bleeding in either the patient or her family.

On examination she was distressed but afebrile. There was $90^{\circ}$ flexion at the right hip with severe pain elicited by extension. There were no abdominal masses or neurological signs in the right leg.

Investigations revealed haemoglobin $11.0 \mathrm{~g} / \mathrm{dl}$, leucocyte count $10.5 \times 10^{9} / 1$ and platelets $376 \times 10^{9} / 1$. Plain abdominal X-rays were normal and an abdominal ultrasound scan unhelpful. However, a computed tomographic scan showed a right psoas mass that was felt to be due to either an abscess, tumour or haematoma.

Surgical exploration was performed, and a large psoas haematoma was identified and evacuated. Persistent bleeding from the wound was noted, however, and a coagulation screen revealed a

Correspondence: G.R. Standen, Ph.D., M.R.C.P., M.R.C.Path.

Accepted: 29 March 1994 prolonged activated partial thromboplastin time of 52 seconds (control: $28-40$ seconds).

Clotting factor assays identified an isolated ${ }^{\infty}$ factor IX deficiency of $15 \mathrm{U} / \mathrm{dl}$ (normal range: $50-150 \mathrm{U} / \mathrm{dl}$ ). She was treated with factor IX concentrate (BPL) for 10 days postoperatively and $\vec{z}$ recovery was uneventful. Subsequent chromosome $O$ analysis on peripheral blood lymphocytes revealed $\Phi$ a normal female karyotype.

The pedigree of the family is shown in Figure $d, \frac{\mathbb{D}}{-}$ together with the factor IX clotting activities of the individual members. DNA analysis was also pertformed and segregation of the intragenic Taq restriction fragment length polymorphism (RFLP) detected by the polymerase chain reaction ${ }^{2}$ is shown. The most likely interpretation of this phenotypic and genotypic data is that both the $\frac{\mathrm{O}}{\mathrm{O}}$ propositus (III-I) and her mother (II-3) are carriers $\cong$ of a factor IX gene mutation, which had arisen in a $\overrightarrow{\overrightarrow{0}}$ germ cell of the maternal grandfather (I-2).

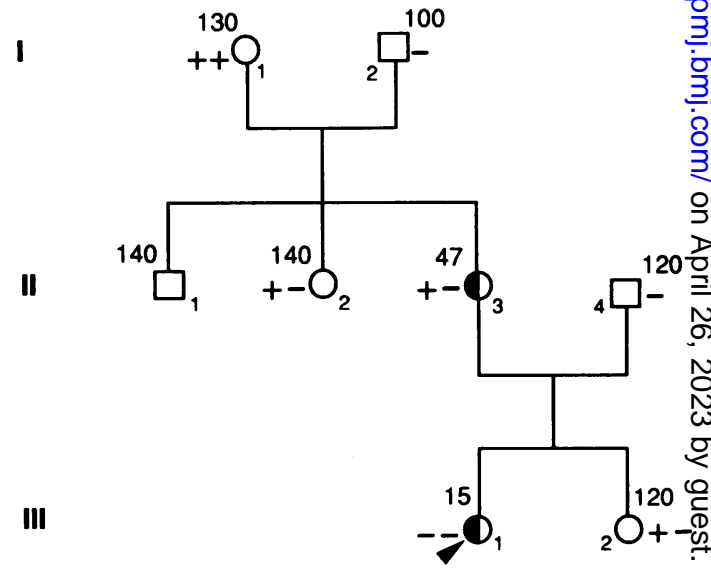

Figure 1 Pedigree of family showing factor IX clotting activity $(\mathrm{U} / \mathrm{dl})$ and Taql RFLP analysis $(+-)$ for $\overrightarrow{\mathbb{D}}$ individual members. 
Manifestations of the deficiency in the female propositus results from extreme lyonization. This was confirmed by specific mutation diagnosis (kindly performed by Dr P. Green, Paediatric Research Unit, Guy's Hospital). A missense mutation (Cys ${ }^{51} \rightarrow$ Trp) was identified in both the propositus and her mother, but no other family member. This mutation has been registered in the UK database of haemophilia B mutations and pedigrees. $^{3}$

\section{Discussion}

The young female described in this report presented with clinical features suggestive of a psoas haemorrhage. However, the radiological appearances of the psoas mass were non-specific and, in the absence of previous bleeding manifestations or relevant family history, a pre-operative coagulation screen was not performed. Clotting tests undertaken because of excessive postoperative bleeding rapidly led to the diagnosis of factor IX deficiency and appropriate replacement therapy was commenced.

Females with factor IX deficiency are most commonly haemophilia B carriers exhibiting extreme lyonization. Other possible mechanisms include Turner's syndrome/mosaicism, isochromosome $\mathrm{X}$ or $\mathrm{Y}$, and homozygous or double

\section{References}

1. McGraw, R.A., Davies, L.M., Lundblad, R.L., Stafford, D.W. \& Roberts, H.R. Structure and function of factor IX: defects in haemophilia B. Clinics Haematol 1985, 14: 359-383.

2. Bowen, D.J., Thomas, P., Webb, C.E., Bignell, P., Peake, I.R. \& Bloom, A.L. Facile and rapid analysis of the DNA polymorphisms within the human factor IX gene using the polymerase chain reaction. Br J Haematol 1991, 17: 559-560. heterozygous factor IX gene mutations. ${ }^{1}$ As there were no affected male family members, factor IX gene-sequencing studies were performed in both the propositus and her mother, who also had borderline low factor IX activity. The results confirmed that both mother and daughter were carriers of a factor IX gene mutation.

The point mutation identified in this family is previously undescribed and involves a $T \rightarrow G$ transition at nucleotide 10405 of the factor IX gene. This change in exon 4 results in substitution of tryptophan for cysteine within the epithelial growth factor type B domain of the factor IX protein. As the mutation eliminates a disulphide bridge at cysteine 62 , major disruption of local tertiary structure would be expected. The relatively low factor IX activity in the female propositus suggests that a male offspring inheriting the mutation would manifest a severe haemophilia B phenotype. Specific mutation detection provides the future potential for accurate and early prenatal diagnosis in this situation.

The present case emphasizes that $\mathrm{X}$-linked coagulation disorders may be unsuspected in some families if a male offspring fails to inherit the genetic defect. Females who present with bleeding problems suggestive of haemophilia should be investigated fully to exclude symptomatic carriership. Molecular genetic techniques have become important tools for investigating the inheritance patterns in such families.

3. Saad, S., Rowley, G., Green, P.M. \& Giannelli, F. First report on UK database of haemophilia B mutations and pedigrees (1991-1992): an analysis of the first 170 patients. 1994, (in press) 